Revista Monografias Ambientais - REMOA v. 15, n.1, jan-abr. 2016, p.154-167

Revista do Centro de Ciências Naturais e Exatas - UFSM, Santa Maria

\title{
CULTIVOS AGRÍCOLAS E USO DE AGROTÓXICOS EM ASSENTAMENTOS DA REFORMA AGRÁRIA NO RIO GRANDE DO SUL
}

Farm cultures and use of agrochemicals in settlements of agrarian reform in Rio Grande do Sul

\author{
Mauro Barcellos Sopeña, Nayara Pasqualotto, José Geraldo Wizniewsky
}

Universidade Federal de Santa Maria

\begin{abstract}
Resumo
O presente artigo analisa registros recentes sobre o uso de agrotóxicos em assentamentos da reforma agrária no estado do Rio Grande do Sul. Recorre-se ao comportamento dos dados de sete diferentes cultivos agrícolas, promovendo uma discussão paralela com os indicadores divulgados pela principal agência de vigilância sanitária brasileira (ANVISA). Os resultados globais demonstram forte associação entre os registros da agência e a ocorrência de aplicação de agrotóxicos entre os assentamentos pesquisados.
\end{abstract}

Palavras-chave: Agrotóxicos. Assentamentos da reforma agrária. Consumo de agrotóxicos.

\section{Abstract}

This article analyzes recent records on the use of pesticides in agrarian reform settlements in the state of Rio Grande do Sul, Brazil. It resorts to the behavior of data from seven different agricultural crops, promoting a parallel discussion with leading indicators released by the Brazilian Sanitary Surveillance Agency (ANVISA). The overall results show a strong association between agency records and the occurrence of pesticide application between the settlements studied.

Keywords: Agrochemical. Agrarian reform settlements. Consumption of Agrochemical. 


\section{Introdução}

Entre os diferentes elementos teóricos preconizados pela literatura sobre agroecologia, o uso de recursos de base ecológica parece representar um dos pontos recorrentes entre autores da área. Em oposição ao que se apregoa em termos agroecológicos, muitos cultivos agrícolas, no entanto, registram práticas convencionais dissociadas dos preceitos mais gerais daquela literatura, se observando, neste cenário, a persistência do uso de agrotóxicos em diferentes culturas agrícolas. Como forma de explorar e contribuir para o debate deste fenômeno, o presente artigo analisa registros recentes sobre o uso de agrotóxicos em assentamentos da reforma agrária no Estado do Rio Grande do Sul. Recorre-se ao comportamento dos dados de sete diferentes cultivos agrícolas, promovendo uma discussão paralela com os indicadores divulgados pela principal agência de vigilância sanitária brasileira, a ANVISA.

Considera-se importante, mesmo que de forma breve, destacar os principais conceitos trabalhados na abordagem agroecológica. Com este intuito, realiza-se sucinta revisão teórica que engloba um conjunto de elementos imprescindíveis na análise conceitual, destacando a proeminência da visão sistêmica, própria da área. Ressalta-se ainda, a noção de coevolução como forma de compreender a proposta científica da agroecologia e sua forte negação à ciência ortodoxa que, do ponto de vista epistemológico, careceria de reforma.

O tratamento dos dados é, assim, discutido no âmbito agroecológico. Reconhece-se, no entanto, que a discussão sobre o uso de agrotóxicos nos assentamentos da reforma agrária compreende apenas uma parcela do debate agroecológico. $\mathrm{O}$ artigo, portanto, não se integra ao discurso da agricultura "ecologizada" e simplista, senão, contribui para o entendimento parcial do fenômeno. Assim, a principal fonte de dados do trabalho está representada pelas informações contidas no Sistema Integrado de Gestão Rural (SIGRA/RS), ferramenta de pesquisa e assistência disponibilizada pelo Incra aos assentamentos da reforma agrária no Rio Grande do Sul (ATES1). O sistema consolida, a cada ano, informações diversas distribuídas em núcleos operacionais que incorporam, entre outros dados, informações sobre o uso de agrotóxicos por famílias - objeto deste estudo. O indicador, naquele banco de dados, é denominado de "veneno". Neste trabalho o uso do termo "agrotóxico" compreenderá todos os tipos de defensivos e outros recursos empregados nas atividades produtivas.

Em adição à análise dos dados do SIGRA/RS, recorre-se aos estudos promovidos pela Agência Nacional de Vigilância Sanitária - Anvisa, como forma de averiguar índices de contaminação por agrotóxicos nas culturas selecionadas - sejam elas oriundas da aplicação de herbicidas, inseticidas, fungicidas, acaricidas, entre outros. O estudo mais importante para esta tarefa é o Programa de Análise de Resíduos de Agrotóxicos em Alimentos (PARA), criado em 2001. Nele, diferentes amostras são avaliadas com o objetivo de garantir a segurança alimentar do consumidor e a saúde do trabalhador rural.

Fontes diversas - sejam elas acadêmicas ou vinculadas às diferentes mídias, destacam o Brasil como um grande consumidor de agrotóxicos². Em trabalho divulgado pela Assembleia Legislativa do Estado do Rio Grande do Sul (AL/RS), o país é citado como o primeiro colocado no ranking mundial de vendas do produto, consumindo mais de um milhão de toneladas (o equivalente a mais de 1 bilhão de litros) de venenos (AL/RS, 2013, p. 11) em 2009. Para o referido estudo, o uso crescente de agrotóxicos está se tornando uma questão de saúde pública e tende a aumentar seus efeitos nocivos com o avanço do agronegócio brasileiro: Somos a agricultura mais envenenada do mundo. São mais

\footnotetext{
${ }^{1}$ Programa de Assessoria Técnica, Social e Ambiental executado para assentamentos da reforma agrária.

2 Para LONDRES (2011, p. 19), na última década o [...] o uso de agrotóxicos no Brasil assumiu as proporções mais assustadoras. Entre 2001 e 2008 a venda de venenos agrícolas no país saltou de pouco mais de US\$ 2 bilhões para mais US\$ 7 bilhões, quando alcançamos a triste posição de maior consumidor mundial de venenos. Foram 986,5 mil toneladas de agrotóxicos aplicados. Em 2009 ampliamos ainda mais o consumo e ultrapassamos a marca de 1 milhão de toneladas - o que representa nada menos que 5,2 kg de veneno por habitante! Os dados são do próprio Sindag (Sindicato Nacional da Indústria de Produtos para Defesa Agrícola), o sindicato das indústrias de veneno.
} 
de cinco quilos de venenos por habitante/ano. É a dependência química do agronegócio (AL/RS, 2013, p. 15).

Neste cenário importa, pois, avaliar diferentes indicadores que permitam compreender o comportamento da atividade agrícola, em diferentes realidades. O sentido agroecológico da produção é também destacado em fontes do Programa de Ates. Em manual operacional deste programa, indicações claras são encontradas. Entre seus princípios está: adotar uma abordagem multidisciplinar e interdisciplinar, estimulando a adoção de novos enfoques metodológicos participativos e de um paradigma tecnológico baseado nos princípios da agroecologia (MDA, 2008, p. 65). A opção pela abordagem agroecológica é clara:

\begin{abstract}
A estratégia de conversão agroecológica preconizada pelo Programa de ATES busca ter um impacto nos agroecossistemas familiares e na qualidade de vida das famílias. Assim, esperasse que as propostas inovadoras agroecológicas produzam resultados em duas frentes. Por um lado, espera-se um incremento na produção agrícola e pecuária, o que tem um impacto na renda, mas também reforça a segurança alimentar das famílias. Ao mesmo tempo, as inovações também tentam fazer com que as unidades familiares tenham uma maior estabilidade e maior resistência, o que implica na preservação da base de recursos destes sistemas produtivos (MDA, 2008, p. 45).
\end{abstract}

A importância desta discussão pode igualmente ser percebida pelas diversas recomendações do estudo anteriormente apontado. Entre elas, a AL/RS aconselha articulações conjuntas entre os diversos atores, fortalecimento dos trabalhos de vigilância e assistência técnica rural, promoção de campanhas educativas, limitação de importações de agrotóxicos, valorização de uma agricultura sustentável, incentivo à produção orgânica, reavaliação de ingredientes ativos de importância toxicológica, entre outras.

Com base neste delineamento, o trabalho está dividido em cinco partes. Além desta (i) introdução, conta com (ii) os procedimentos metodológicos empregados; (iii) uma breve revisão da literatura sobre o pensamento agroecológico; (iv) a análise de dados recentes sobre o uso de agrotóxicos em cultivos agrícolas selecionados e, por fim, (v) as conclusões do estudo.

\title{
2 Procedimentos Metodológicos
}

A pesquisa utiliza-se de dados secundários coletados em duas fontes: (a) o SIGRA/RS - Sistema Integrado de Gestão Rural e (b) a ANVISA - Agência Nacional de Vigilância Sanitária. O objetivo geral do trabalho, o de analisar dados sobre uso de agrotóxicos em assentamentos da reforma agrária no Rio Grande do Sul, sustenta-se no aparato teórico da agroecologia. De outro modo, pretende cotejar os dados selecionados com os resultados encontrados pela Anvisa, procurando estabelecer associações de forma particular, ou seja, para cada produto analisado.

Os dados e indicadores disponibilizados pelo SIGRA/RS são de particular importância para a pesquisa e para a assistência técnica aos assentados da reforma agrária no estado gaúcho. Segundo informações do INCRA/RS, esta ferramenta de gestão objetiva reunir maiores detalhes e mais dados para melhorar o atendimento aos beneficiários da reforma agrária no estado (INCRA, 2013). O sistema é operado juntamente com a equipe de articuladores da Universidade Federal de Santa Maria (UFSM). Informações disponibilizadas pelo INCRA/RS permitem identificar que a proposta

é reunir as informações, complementando as já existentes, através de um questionário que inclui desde o histórico da família (sua origem), perguntas sobre saneamento básico, abastecimento de água e energia, telefonia, transporte e saúde, até a identificação dos sistemas de produção de cada família. Para isso, o tempo das visitas técnicas foi ampliado em 45 minutos, chegando, em média, a 3h15min por família. As visitas estão previstas no contrato de assistência técnica do 
Incra com as prestadoras, sendo uma das ações contabilizadas no pagamento das equipes (INCRA, 2013).

O trabalho realizado pela equipe é dividido por núcleos operacionais (NOs), totalizando 19 unidades, de acordo com a localização ${ }^{3}$. A Figura 1 ilustra recente encontro de capacitação de técnicos do INCRA sobre o sistema SIGRA/RS.

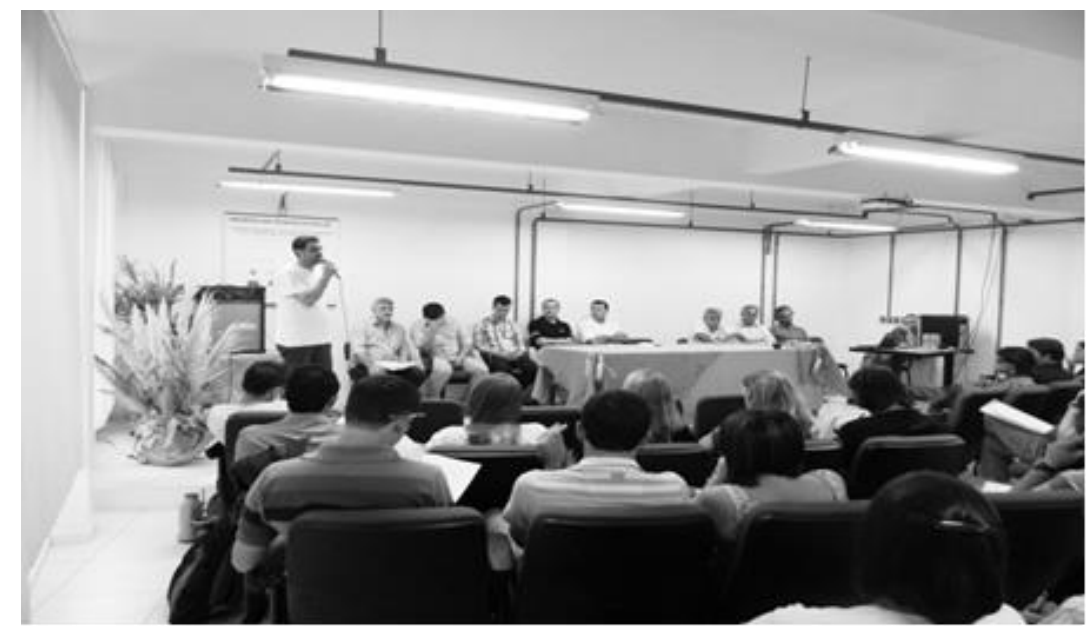

Figura 1: Encontro de capacitação de técnicos promovido pelo INCRA/RS.

Fonte: INCRA, 2013. Ascom Incra/RS (créditos: Maurem Silva).

Indicadores sobre o uso de agrotóxicos por número de famílias assentadas são disponibilizados no sistema e consolidados a cada final de período (ano). Os dados coletados referem-se aos anos de 2012 e 2013; única série existente. Os dados globais, referentes à produção total realizada pelas famílias, foram filtrados e separados para a análise específica em sete diferentes cultivos: arroz, cenoura, laranja, maçã, morango, pimentão e pepino. A escolha proposital deste conjunto selecionado de produtos permite que os registros sejam discutidos com base nos dados da segunda fonte de pesquisa utilizada (ANVISA); ademais, esta seleção de culturas associa-se, de forma recorrente, ao uso de agrotóxicos em sua composição.

Estudos toxicológicos realizados pelo Programa de Análise de Resíduos de Agrotóxicos em Alimentos (PARA-ANVISA) representam importante fonte de dados sobre o uso indevido de agrotóxicos nas culturas selecionadas no Brasil. Embora não se possa viabilizar a análise comparativa destas informações com os dados do SIGRA/RS4, os resultados encontrados naqueles estudos são, contudo, imprescindíveis no sentido de um indicativo sobre os produtos em que os níveis toxicológicos são altos e alarmantes do ponto de vista social e, assim, podem ser cotejados com a ocorrência do uso de agrotóxicos em assentamentos.

A sequência metodológica empregada no trabalho pode ser ilustrada, conforme a Figura 2.

\footnotetext{
${ }^{3}$ Segundo informações do Programa de ATES/RS, trata-se de um serviço criado pelo INCRA para prestar assessoria técnica, social e ambiental para as famílias assentadas pela reforma agrária, de forma integral e continuada. O propósito é assessorar as famílias nos aspectos econômicos, sociais e ambientais, de modo a melhorar a qualidade de vida das famílias, o aperfeiçoamento nos processos de gestão do lote, produção, beneficiamento e comercialização, além de outras questões como bem estar, saúde, educação, saneamento básico, gênero, juventude, preservação do meio ambiente, etc. Para Operacionalização do serviço de ATES os assentamentos foram agrupados regionalmente formando os Núcleos operacionais (NOs) que compõem a célula base do programa de ATES. É em torno do NO que se organiza o trabalho de cada equipe técnica.

4 Uma análise estatística (econométrica) e comparativa dos dados apontados se torna inviável pelo fato de que as amostras utilizadas são distintas, assim como as regiões pesquisadas e as fontes de dados (metodologias distintas). Ao contrário, conforme objetiva este estudo, se pode determinar a evolução do fenômeno nas duas fontes de dados, estabelecendo, quando possível, convergências e associações pertinentes.
} 


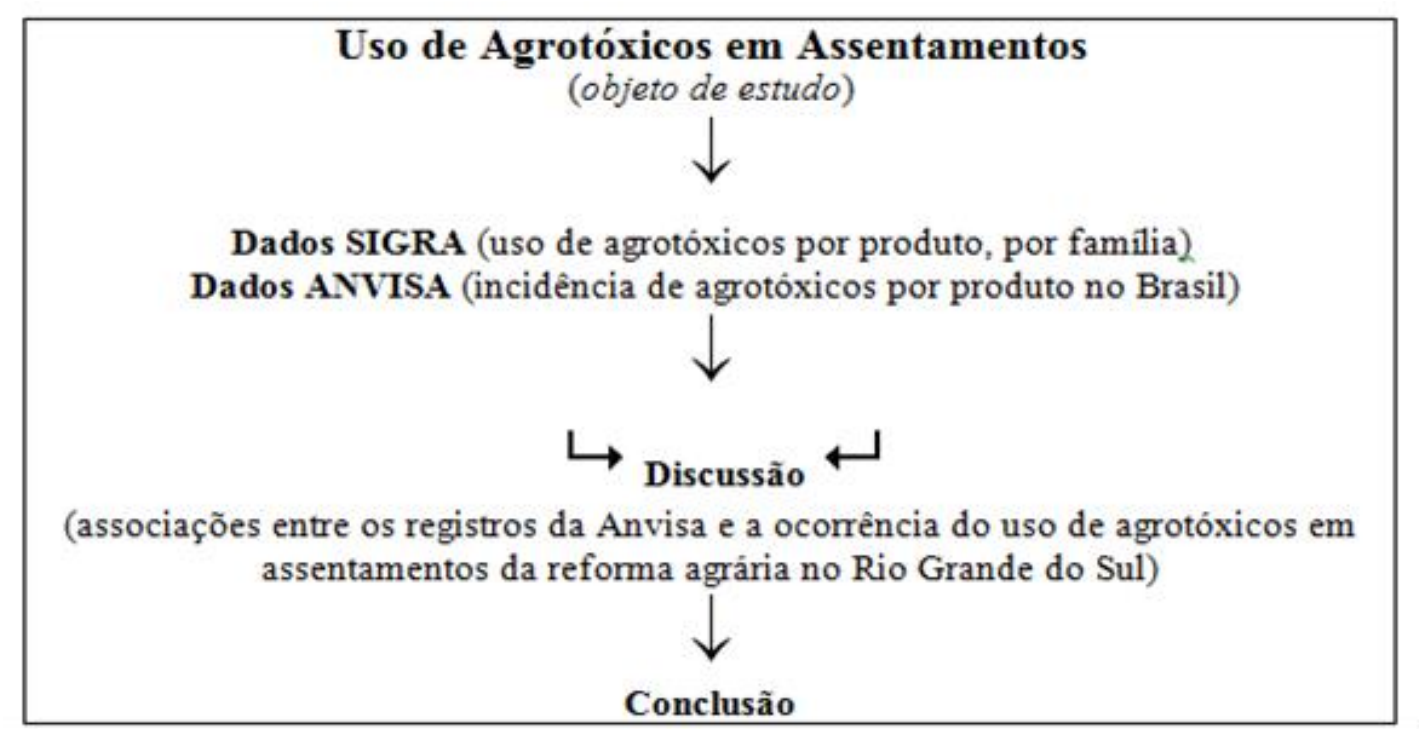

Figura 2: Procedimentos metodológicos da pesquisa. Fonte: elaboração própria.

Do ponto de vista teórico, recorre-se aos preceitos mais gerais da agroecologia. Sustenta-se aqui, que o debate dos grandes paradigmas promovido nesta área de pesquisa é mais valioso para a compreensão das questões que envolvem o uso de agrotóxicos do que estudos mais pontuais. Em verdade, a questão agrária não pode ser apreendida sem a amplitude de conceitos, característica que parece própria da proposta agroecológica. Um breve debate acerca destes conceitos é oferecido a seguir.

\section{A PERSPECTIVA AGROECOLÓGICA: uma revisão dos principais conceitos}

Em importante trabalho sobre a temática agroecológica, ALTIERI (1999) centra os estudos agroecológicos na incorporação de ideias que apresentem um enfoque da agricultura ligado ao meio ambiente, com sensibilidade quanto à questão social e com um conceito de produção que garanta a sustentabilidade ecológica. Em complemento, considera o autor a pertinência de estudos que se apoiem em diferentes disciplinas ${ }^{5}$. A aplicação dos conceitos agroecológicos igualmente assume destaque em GLIESSMAN (2003). Em seus escritos, ao utilizar a metáfora de una piscina en un rio, fica evidente a defesa de que, na agroecologia, é importante considerar não somente uma parcela ou uma parte da atividade que se queira desenvolver, mas o todo. Assim, a observação do sistema como um todo não deve ser abandonada e o conceito de ecossistema torna-se fundamental: sistema funcional de relaciones complementarios entre organismos vivos y su ambiente, delimitado por bordos escogidos arbitrariamente, que en el espacio y el tiempo parece mantener un equilibrio estable pero dinâmico (GLIESSMAN, 2003, p. 107). Nesta linha de interpretação, o uso de fontes de energia renováveis deve ser uma preocupação das sociedades humanas, com a manutenção de um equilíbrio ecológico à luz dos processos de resiliência observados. Assim, conhecimentos tradicionais importam: (5 A capacidade de reunir diferentes áreas do conhecimento em torno dos estudos agroecológicos parte de um pressuposto bem objetivo, ou seja, considera que uma agricultura atomística e passível de subdivisão (disciplinas) não contempla a realidade de forma integral e holística. Em trabalho de SANTIAGO (2002), encontra-se uma reflexão acerca da incorporação da agroecologia em instituições de ensino superior voltadas à educação agrícola. 
es la experiencia local de cultivar usando prácticas que tienen raíces en el multitud de generaciones de vivir y trabajar dentro de los limites de ese entorno. Juntamos ambos enfoques cuando trabajamos con agricultores en el proceso de convertirse a prácticas de manejo más ambientales, y por ende alcanzamos su potencial por contribuir a la sostenibilidad de largo plazo. Esta transición ya se está llevando a cabo. Muchos agricultores, a pesar de las presiones económicas intensas, se encuentran en el proceso de convertir sus granjas hacia un diseño y manejo más sostenible (GLIESSMAN, 2003, p. 115).

Um dos conceitos mais importantes desta área do conhecimento - considerado aqui como um conceito-chave para a compreensão dos enfoques agroecológicos, é o conceito de coevolução. Nesta ótica, defende-se a existência de certa unicidade à relação natureza-sociedade ${ }^{6}$. O princípio da coevolução é central, inclusive, na interpretação sobre resiliência. Para GUZMÁN (1999, p. 88), poderse-ia sintetizar este conceito a partir de um novo paradigma ecológico, capaz de superar o atomismo, mecanicismo, universalismo, objetivismo y monismo7 ${ }^{7}$ Em trabalho de CALDART (2012, p. 62), o núcleo desta abordagem é assim apresentado:

\footnotetext{
Um dos conceitos-chave que orientam teórica e metodologicamente a agroecologia é o de agroecossistema, unidade de análise que permite estabelecer um enfoque comum às várias disciplinas científicas. Um agroecossistema é, em resumo, um ecossistema artificializado pelas práticas humanas, por meio do conhecimento, da organização social, dos valores culturais e da tecnologia, de maneira que sua estrutura interna é "uma construção social produto da coevolução entre as sociedades humanas e a natureza.
}

Num sentido amplo, se concebe uma dissensão entre o enfoque da corrente agroecológica (em um viés que defende a agricultura de base ecológica e amparada em preceitos de sustentabilidade) e a corrente da agricultura ecologizada, desprovida de sentido sustentável e direcionada à demanda e aos nichos de mercado. O primeiro enfoque atende ao significado de coevolução, que contempla tanto o lado social como o ecológico de forma integrada, o que corresponde à temática da ecosociologia ${ }^{8}$ (GUZMÁN; NAVARRO, 2000). No segundo, carente de um sentido agroecológico, observa-se o uso mercadológico empregado à agricultura.

A centralidade da obra de COSTABEBER e CAPORAL (2004) pode ser detectada no esforço de construir conceitualmente o significado de agroecologia. Os autores consideram esta tarefa imprescindível tanto em termos práticos (como na formulação de programas e políticas públicas), quanto em termos científicos; notadamente quando se verifica a ocorrência de interpretações errôneas entre este conceito e os modelos de agricultura alternativa ( 6 Pelo sentido empregado no termo, adiante abordado, não se considera uma correspondência direta com o sentido evolucionário empregado no âmbito do darwinismo (seleção natural), muito embora se conceba a noção de que sociedade e natureza evoluem de forma conjunta. Neste âmbito de análise, faria sentido, por exemplo, considerar a influência política exercida sobre o consumo de alimentos, escopo de pesquisa que vincula natureza e sociedade. Sobre este tópico específico, ver trabalho de PORTILHO; et al (2011). A percepção e a influência recíproca entre o agricultor familiar e a natureza igualmente poderia ser entendida no debate sobre a ocorrência do uso de agrotóxicos em diferentes cultivos. Uma sugestão de leitura particularmente referida a esta discussão é o texto de BRITO; et al, 2009.

7 Para o MDA (2008), os serviços de Ates são pautados nos conceitos e princípios da Agroecologia, [...] complexo enfoque científico que correlaciona diversas disciplinas de forma sistêmica de modo a proporcionar as bases (princípios, conceitos e metodologias) para apoiar o processo de transição do atual modelo de agricultura convencional para estilos de agricultura sustentáveis. Então, mais do que uma disciplina específica, a Agroecologia se constitui num campo de conhecimento que reúne várias "reflexões teóricas e avanços científicos, oriundos de distintas disciplinas", que têm contribuído para conformar o seu atual corpus teórico e metodológico (Guzmán Casado et al., 2000). 
8 [...] desde una perspectiva ecosociológica, las relaciones de producción poseen los factores reproductivos, tanto a nivel biótico como social y cultural, al generar la apropiación ecológica y social del excedente. Su análisis en términos de intercambios entre los agentes sociales y las esferas natural, agroecológica y social (mercado) en cada uno de los procesos de trabajo puede permitirnos caracterizar la producción y reproducción real [...] en las diferentes formas de exploración que se articulen, conformando éstas los límites del juego donde los agentes sociales desarrollan sus estrategias de reproducción social (GUZMÁN e NAVARRO, 2000, p. 35).

)$:$

[...] não se deve entender como agricultura baseada nos princípios da Agroecologia aquela agricultura que, simplesmente, não utiliza agrotóxicos ou fertilizantes químicos de síntese em seu processo produtivo. No limite, uma agricultura com esta característica pode corresponder a uma agricultura pobre, desprotegida, cujos agricultores não têm ou não tiveram acesso aos insumos modernos por impossibilidade econômica [...] (COSTABEBER; CAPORAL, 2004, p. 8).

Em adição a esta formulação, os autores destacam a importância de se vislumbrar outros elementos presentes na noção de sustentabilidade, sejam eles econômicos, sociais, culturais, políticos, éticos ou ambientais. Neste sentido, o processo de transição ecológica representaria o meio de atingir o desenvolvimento sustentável de territórios rurais, em oposição ao modelo convencional hegemônico. Ademais, a perspectiva ecológica, por contemplar diversas áreas (enfoque sistêmico), permite, inclusive, a revisão de valores sociais estabelecidos, especialmente aqueles de cunho local, como no caso da abordagem territorial do desenvolvimento. A transição ecológica, portanto, passaria por quatro níveis: (a) maior eficácia na utilização de insumos; (b) reavaliação e substituição da utilização de insumos malignos por outros (alternativos); (c) redesenho dos agroecossistemas com sentido de longo prazo (novos processos ecológicos seriam aqui complementares aos dois primeiros níveis) e (d) a educação dos consumidores quanto aos impactos ambientais e sociais inerentes aos produtos que esses consomem (GLIESSMAN et. al., 2007).

As proposições agroecológicas são, em essência, críticas quanto à natureza positivista da ciência (GUZMAN, 1999). Em muitas pesquisas teóricas conduzidas no sentido de avaliar a questão epistemológica que cerca o debate, verifica-se a exposição do predomínio de um viés positivista na ciência que parece, segundo a literatura, ter importante influência sobre a relação que se estabelecera entre sociedade e natureza. Para ALTIERI (1999, p. 17),

\footnotetext{
esta transición de las epistemologías cambió el enfoque de la naturaleza, de una entidad orgánica, viviente, se convirtió en una máquina. De manera creciente este enfoque hizo hincapié en el lenguaje científico, una forma de referirse al mundo natural que esencialmente rechazaba toda otra forma de conocimiento científico como superstición. En efecto, desde los tiempos de Condorcet y Comte, el desarrollo de las ciencias se identifica con el triunfo de la razón sobre la superstición. Esta posición, unida a un punto de vista muchas veces despectivo sobre las habilidades de los pueblos rurales en su generalidad, y en especial las de los pueblos colonizados, contribuyó más aún a oscurecer la riqueza de muchos sistemas de conocimiento rural cuyo contenido era expresado en una forma discursiva y simbólica.
}

Em trabalho de GOMES e ROSENSTEIN (2000), contempla-se uma discussão epistemológica da ciência e da tecnologia, defendendo a pluralidade como fator essencial no âmbito do conhecimento agrário, com vistas ao debate agroecológico. Os autores não defendam um sistema dual simples (modelo antigo versus modelo novo), mas pluralista. Nesta perspectiva, o conhecimento tradicional estaria "sob suspeita", no sentido de que entendem que o 
positivismo nas ciências se apoderou do homem [...] com o legado positivista, ou "concepción heredada" da ciência, o desenvolvimento científico é concebido como um processo regulado por um rígido código de racionalidade somente manejado com destreza pelos cientistas. Esta concepção continua as ideias do "cientificismo" posto em circulação por Augusto Comte.

A revisão de pré-concepções epistemológicas parece importante no sentido de relativizar a "verdade" científica. Como há forte defasagem na capacidade que o conhecimento agrário tem de absorver maior pluralismo, a

\begin{abstract}
tomada de consciência sobre os efeitos do modelo produtivista de desenvolvimento na agricultura, sob o paradigma da revolução verde, gerou a busca de alternativas de resistência em diversos níveis da sociedade. Essa resistência oscila desde denúncias de ecólogos urbanos sobre problemas ambientais mais amplos até a proposta de adoção de formatos tecnológicos orientados para a sustentabilidade. A origem do discurso é diversa e plural, contemplando desde questões surgidas nas academias até a busca de soluções desenvolvidas pelos próprios agricultores. (GOMES; ROSENSTEIN, 2000, p. 37).
\end{abstract}

Para os pesquisadores, trata-se de alertar para a necessidade de superação da hegemonia da ciência moderna (sua cara supremacia) sem, no entanto, reconhecer as vitórias conquistadas e suas expectativas9. Novas formas de saber, em verdade, são necessárias para a sociedade e, assim, se pode pensar em uma ciência prudente, uma nova configuração para o saber. Deve-se, portanto, superar a dicotomia entre contemplação e ação e o falso fosso entre a verdade científica da ciência (a ciência em si) e a verdade social da ciência (a tecnologia), já que hoje não tem sentido a distinção entre ciência pura e ciência aplicada (GOMES; ROSENSTEIN, 2000, p. 48). Ademais, como destacado pelos autores, outras formas de conhecimento são evidentes e importantes, tais como aqueles provenientes de saberes locais, tradicionais ou indígenas, o que os pesquisadores denominam de epistemologia natural.

Encontra-se outra pertinente análise epistemológica no texto de GUZMÁN (2002), porém, com maior vínculo sobre a natureza social que a agroecologia contempla. A análise se inicia com uma crítica à parcelização disciplinar e a consequente defesa do pluralismo. $\mathrm{O}$ autor destaca a viabilidade de construção de uma agricultura participativa como meio de romper com o discurso agronômico convencional (GUZMÁN; 2002, p. 24). Assim, a

perspectiva estrutural da Agroecologia permite [...] preparar o terreno para o desenvolvimento de uma agricultura participativa, fazendo emergir, assim, uma dimensão global de busca de melhorias no nível de vida das comunidades rurais envolvidas [...] Assim, é possível pensar um desenvolvimento rural desde a agricultura participativa como o conjunto de esquemas de desenvolvimento que partem do reconhecimento da necessidade e/ou do interesse de trabalhar com as comunidades locais na identificação, no desenho, na implementação e na avaliação dos métodos de desenvolvimento endógeno mais adequados para a resolução de seus problemas. A ruptura epistemológica com o desenvolvimento rural convencional surge da experiência acumulada nos últimos trinta anos na América Latina, na África e na Ásia, a partir do reconhecimento de que os agricultores não só têm um amplo conhecimento dos seus sistemas agrícolas, senão que, ademais, são capazes de dirigir provas e experimentos. A Agroecologia pretende, assim, dotar os agricultores do poder da participação (GUZMÁN; 2002, p. 25).

ALTIERI e TOLEDO (2011) oferecem trabalho importante e recente acerca do potencial que iniciativas agroecológicas trazem para a realidade latino-americana, em confronto com abordagens ligadas aos processos agroindustriais e baseadas em exportações agrícolas. Nesta tarefa, parece central para os autores que uma "revolución agraria" tenha, em seu núcleo, uma mínima dependência de agrotóxicos ${ }^{10}$ e de energia e, por outro lado, não se limite a práticas do tipo produção orgânica, senão, apresente amplitude, inclusive, aos agricultores. Nesta perspectiva ampla, muitos elementos devem ser atingidos, entre eles: a valorização das experiências dos agricultores, as comunidades locais, a horizontalidade no planejamento, a diversidade, os mercados locais e a segurança alimentar. 
Pelo exposto, se pode verificar um conjunto de elementos imprescindível na abordagem agroecológica. Um viés sistêmico, acompanhado da noção de coevolução apresenta-se como nuclear nesta área do conhecimento. De outro lado, pela crítica epistemológica que apresenta, a negação do enfoque científico hegemônico é estabelecida no sentido de abrir espaço para formas alternativas de conhecimento que superem, inclusive, a parcelização disciplinar. Elementos em destaque, como a agricultura participativa e a epistemologia natural são, portanto, representativos nesta visão inovadora de ciência que a agroecologia pretende suportar. Despreza-se na literatura a noção simplista e equivocada de que a agroecologia compreende aquela agricultura que não usa agrotóxico (agricultura ecologizada). Assim, sustenta-se a agroecologia como aquele ramo do conhecimento que, efetivamente, ampara-se nos preceitos da sustentabilidade. ( 9 Para ALMEIDA (2003, p. 15), no entanto, a luta agroecológica poderá provocar uma autêntica e profunda transformação no campo político [...], desde que saiba "costurar" as alianças capazes de provocar uma ampliação de seu poder de luta. Essas lutas deverão encaminhar-se na direção da convergência (e da complementaridade) com outras formas de combate e de movimentos sociais, a fim de fazer dessa ação a precursora por excelência de um movimento social mais amplo e dirigido contra a tecnocracia que dita as necessidades de uma população. Por enquanto, a agroecologia é a expressão de iniciativas de grupos ou agentes sociais mais ou menos isolados, ainda pouco orgânicos, com resultados técnicos e sociais em diferentes amplitudes, agentes estes que poderão vir a integrar um movimento social, mas que, atualmente, não constituem e não representam um movimento social. Para CALDART (2012, p. 61), foi somente a partir de 1989 que o termo agroecologia começou a ser utilizado no Brasil, com a publicação do livro Agroecologia: as bases científicas da agricultura alternativa, de Miguel Altieri (1989), podendo, portanto, ser considerado como um debate relativamente recente.

10 Segundo CALDART (2013, p. 91), no Brasil, o Ministério da Saúde, por meio da Agência Nacional de Vigilância Sanitária (Anvisa), monitora a presença de 234 ingredientes ativos em vinte alimentos. Para o ano de 2009, os resultados mostraram que $29 \%$ deles apresentavam resultados insatisfatórios, seja por estarem acima do limite máximo de resíduos permitido ( $>$ LMR), seja por apresentarem resíduos de agrotóxicos não autorizados e não adequados para aquele cultivo (NA), seja por esses dois motivos associados.

${ }^{11}$ No Brasil, o tema é regulamentado pela Lei Federal 7802/1989 e pelo Decreto N. 4.074/2002. Segundo aponta LONDRES (2011, p. 99), se a legislação sobre o uso de agrotóxicos fosse cumprida por todos os agentes da cadeia produtiva, os danos seriam minimizados de forma considerável. A autora ainda aponta a Constituição Federal (Art. 196 e 225) como a Lei maior que apresentaria parâmetros sobre o uso de agrotóxicos e a Lei 9.249/96 e Decreto 2018/96, que limitam a propaganda sobre agrotóxicos para produtores.)

\section{CULTIVOS AGRÍCOLAS SELECIONADOS: análise de dados recentes}

O registro acerca do uso de agrotóxicos ${ }^{11}$ por número de famílias assentadas está arranjado para os anos de 2012 e 2013, entre sete cultivos agrícolas diferentes. Em uma primeira aproximação analítica dos dados da Tabela 1, é possível notar um aumento no número geral de famílias pesquisadas em 2013, especialmente para os cultivos de arroz, laranja e morango. O contrário é notório para produtos como cenoura e pepino. A despeito das causas destas variações relativamente abruptas do primeiro para segundo ano, as informações mostram-se relevantes e pertinentes quanto à ocorrência de agrotóxicos entre famílias assentadas. Em todos os registros, por produto e por período, fica evidente que o número de registro de famílias que não empregam agrotóxicos por cultura é sempre superior àqueles que os utilizam. 
TABELA 1: OCORRÊNCIA DE APLICAÇÃO DE AGROTÓXICOS EM CULTURAS POR NÚMERO DE FAMÍLIAS ASSENTADAS NO RIO GRANDE DO SUL - 2012-13

\begin{tabular}{l|c|c|c|c|c|c}
\hline \multirow{2}{*}{$\begin{array}{c}\text { Cultivos } \\
\text { Agrícolas }\end{array}$} & \multicolumn{2}{|c|}{$\mathbf{2 0 1 2}$} & \multicolumn{2}{c|}{$\mathbf{2 0 1 3}$} & \multicolumn{2}{c}{ Total de casos } \\
\cline { 2 - 7 } & Com uso & Sem uso & Com uso & Sem uso & $\mathbf{2 0 1 2}$ & $\mathbf{2 0 1 3}$ \\
\hline Arroz & 251 & 322 & 290 & 396 & 573 & 686 \\
\hline Cenoura & 13 & 18 & 3 & 7 & 31 & 10 \\
\hline Laranja & 7 & 375 & 4 & 558 & 382 & 562 \\
\hline Maçã & 1 & 45 & 1 & 46 & 46 & 47 \\
\hline Morango & 4 & 13 & 0 & 48 & 17 & 48 \\
\hline Pimentão & 0 & 2 & 0 & 4 & 2 & 4 \\
\hline Pepino & 2 & 41 & 2 & 18 & 43 & 20 \\
\hline TOTAL & $\mathbf{2 7 8}$ & $\mathbf{8 1 6}$ & $\mathbf{3 0 0}$ & $\mathbf{1 . 0 7 7}$ & $\mathbf{1 . 0 9 4}$ & $\mathbf{1 . 3 7 7}$ \\
\hline
\end{tabular}

Fonte: Elaboração própria com base nos dados do SIGRA/RS (2013). Dados consolidados, coletados no sistema SIGRA/RS em 11/12/2013.

Em termos relativos, outros resultados são possíveis. A Tabela 2 demonstra que em 2012, arroz, cenoura e morango foram, nesta ordem, os produtos que mais registraram o emprego de agrotóxicos. Em 2013, os resultados são muito semelhantes, senão pela ausência de registros de uso de agrotóxicos no cultivo de morango. Ligeira queda nos percentuais do arroz e da cenoura também é observada.

TABELA 2: TAXA PERCENTUAL DE OCORRÊNCIA DE AGROTÓXICOS POR CULTURAS EM ASSENTAMENTOS NO RIO GRANDE DO SUL - 2012-13

\begin{tabular}{l|c|c|c|c}
\hline \multirow{2}{*}{$\begin{array}{l}\text { Cultivos } \\
\text { Agrícolas }\end{array}$} & \multicolumn{2}{|c|}{$\mathbf{2 0 1 2}$} & \multicolumn{2}{c}{$\mathbf{2 0 1 3}$} \\
\cline { 2 - 5 } & Com uso & Sem uso & Com uso & Sem uso \\
\hline Arroz & 43,80 & 56,20 & 42,27 & 57,73 \\
\hline Cenoura & 41,94 & 58,06 & 30 & 70 \\
\hline Laranja & 1,83 & 98,17 & 0,71 & 99,29 \\
\hline Maçã & 2,17 & 97,83 & 2,13 & 97,87 \\
\hline Morango & 23,53 & 76,47 & 0 & 100 \\
\hline Pimentão & 0 & 100 & 0 & 100 \\
\hline Pepino & 4,65 & 95,35 & 10 & 90 \\
\hline TOTAL & $\mathbf{2 5 , 4 1}$ & $\mathbf{7 4 , 5 9}$ & $\mathbf{2 1 , 7 9}$ & $\mathbf{7 8 , 2 1}$ \\
\hline
\end{tabular}

Fonte: Tabela 1.

Um olhar sobre a evolução dos dados para o período, através da Figura 3, demonstra que o cultivo de pepino registra aumento no uso de agrotóxicos, enquanto que os demais, com exceção da maçã e do morango que se mantiveram estáveis, apresentam queda em sua taxa percentual por período. Em outras palavras, quando os registros de uso de agrotóxicos são analisados no conjunto de informações do ano a que se referem, a taxa percentual sobre o total de famílias pesquisadas parece diminuir, principalmente para os casos em que a porcentagem é acentuada - como o caso do arroz ou da cenoura. O total de casos, igualmente, recua de cerca de $25 \%$ para $21 \%$ no período analisado. 


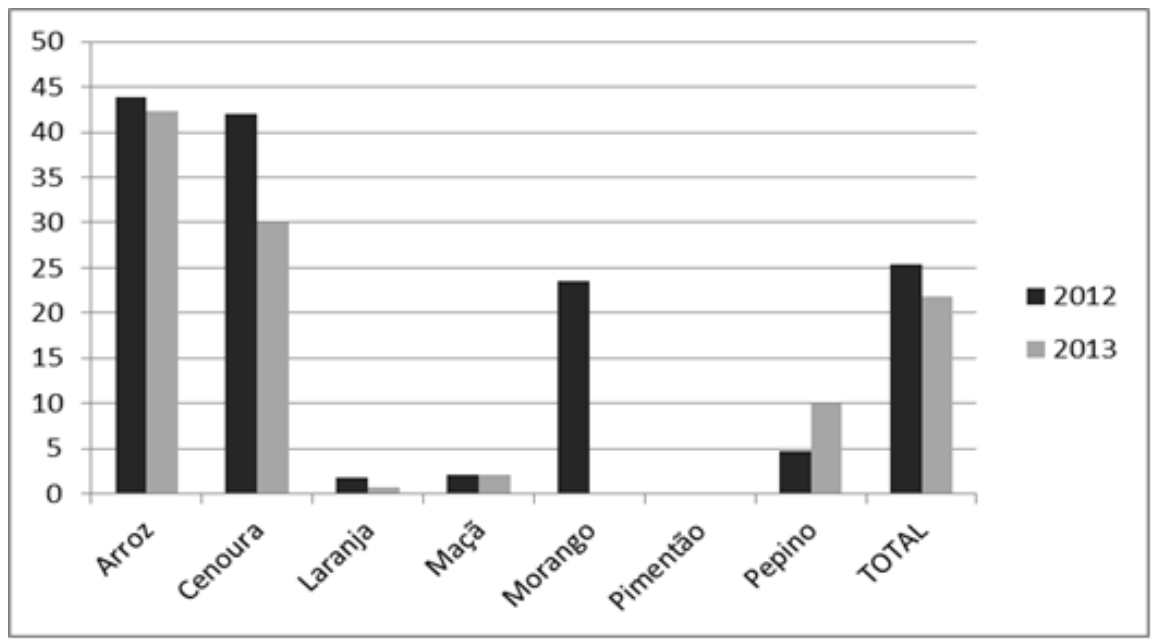

Figura 3: Evolução do uso de agrotóxico por cultura e por família assentada - em \%. Fonte: Tabela 2.

O comportamento de queda observado para o uso de agrotóxicos no âmbito geral deve, no entanto, ser relativizado. Mesmo diante desta recente tendência, considera-se importante observar que os índices de emprego de agrotóxicos nas culturas de arroz, cenoura e morango são significativos, senão elevados. Acrescenta-se nesta ressalva, o incremento percentual de participação no cultivo de pepino, que de aproximadamente $5 \%$ em 2012, passou para $10 \%$ no ano seguinte. A este cenário gerado por meio dos dados do SIGRA/RS (2013) confronta-se, a seguir, resultados divulgados pela Anvisa acerca de dados amostrais para os mesmos produtos anteriormente indicados.

Estudos do Programa de Análise de Resíduos de Agrotóxicos em Alimentos (PARA-ANVISA ${ }^{12}$ ) indicaram que culturas de arroz ${ }^{13}$ e cenoura registram resultados insatisfatórios sobre uso de agrotóxicos nas pesquisas realizadas em 2011. Assim, alimentos como arroz, feijão e cenoura, por exemplo, apresentaram todas as amostras insatisfatórias devido à presença de agrotóxico não autorizado para a cultura, o que evidencia uma irregularidade que necessita ser corrigida (ANVISA, 2013, p. 19). Para a mesma amostra, o pepino obteve $44 \%$ de rejeição e a presença de agrotóxicos de diferentes grupos químicos foi ressaltada pela agência.

Para o ano de 2012, a tendência se repete para os produtos arroz e cenoura: maior índice de irregularidade nas amostras monitoradas em 2012 devido à presença de agrotóxicos não autorizados para a cultura. Em amostras de alimentos como arroz e cenoura, todos os resultados insatisfatórios foram devido à presença de agrotóxicos não autorizados para estas culturas (ANVISA, 2013, p. 31). A amostragem contempla produtos que não estavam presentes em 2011. Morango, laranja, maçã e pepino apresentaram, respectivamente, $59 \%, 28 \%, 8 \%$ e $42 \%$ de resultados insatisfatórios ${ }^{14}$.

Assim como os dados específicos foram tratados no estudo, conclusões de ordem "normativa" são apresentadas. Dois eixos parecem fundamentais na conclusão da agência: (a) a necessidade de formação dos produtores rurais importa na compreensão acerca do uso de agrotóxicos e pode ser ampliada por meio de instituições estaduais de extensão rural e (b) a combinação de diferentes tipos de agrotóxicos potencializa, em muitos casos, os danos causados. Esta combinação é entendida como uma grave irregularidade e, portanto, demonstra a necessidade de maior rigor em termos de fiscalização e articulação entre os agentes envolvidos no processo ${ }^{15}$. Para o caso de produtores assentados, menos capitalizados, o fenômeno pode ser mais rigoroso. A interpretação dos resultados divulgada pela $\mathrm{AL} / \mathrm{RS}(2013$, p. 61) é a de que

[...] é de extrema importância que os órgãos responsáveis pela saúde, trabalho, meio ambiente e agricultura estejam atentos às condições de trabalho dos agricultores, principalmente daqueles com menos recursos financeiros e menor nível de instrução. Eles são responsáveis por grande 
parte da produção de frutas, legumes e verduras consumidos no país e, geralmente, estão mais expostos aos agrotóxicos e às intoxicações agudas e crônicas.

Um desfecho acerca dos dados, de ambas as fontes, torna-se necessário. Em termos globais, alguns apontamentos podem ser registrados a partir dos dados de ambas as fontes. Inicialmente, foi possível notar que o número de famílias que empregam agrotóxicos por cultura é, para todos os casos, inferior àquelas que não adotam esta prática. A incidência do uso está presente em taxas elevadas nas culturas de arroz, cenoura e morango, o que corresponde diretamente com a ocorrência de amostras insatisfatórias detectadas pela Anvisa. O cultivo de pepino, embora com taxas percentuais mais baixas, registrou pontos percentuais de aumento no uso de agrotóxicos para o período.

Para os demais produtos da seleção (laranja, maçã e pimentão), observou-se um comportamento estatístico regular e insignificante quanto ao uso de agrotóxicos. Enquanto a laranja apresentou ligeira queda percentual e participação relativa muito baixa no total de seu grupo, a maçã não obteve variação significativa. Não há nos dados do sistema, registros de famílias que cultivam pimentão. Considerando os estudos da Anvisa para estes produtos, a propensão ao uso de agrotóxicos mostra-se elevada para estas culturas, o que não se observa nos assentamentos pesquisados. ( ${ }^{12} \mathrm{O}$ PARA tem por objetivo verificar se os alimentos comercializados no varejo apresentam níveis de resíduos de agrotóxicos dentro dos Limites Máximos de Resíduos (LMR) estabelecidos pela Anvisa e publicados em monografia específica para cada agrotóxico. Permite, também, conferir se os agrotóxicos utilizados estão devidamente registrados no país e se foram aplicados somente nas culturas para as quais estão autorizados (ANVISA, 2013).

${ }^{13}$ Resultado de destaque foi a deteç̧ão de aldicarbe em uma amostra de arroz. Trata-se do ingrediente ativo de maior toxicidade aguda dentre todos os agrotóxicos de uso agrícola, sendo também o mais empregado, indevidamente, como raticida ilegal, sob a denominação popular de "chumbinho" (ANVISA, 2013, p. 27).

14 A Anvisa verificou que o organofosforado clorpirifós foi detectado em 83 das amostras com resultados insatisfatórios. Ao detalhar as irregularidades deste ingrediente ativo, verificou-se que 42 ocorram em amostras de pepino e o restante em cenoura, morango e abacaxi. O acefato, também organofosforado, apresentou elevado número de irregularidades, sendo detectado em 52 amostras com resultados insatisfatórios (ANVISA, 2013, p. 32).

15 No Brasil, o mercado de agrotóxicos está concentrado (80\%) em seis grandes empresas transnacionais, o que caracteriza um oligopólio. São elas: Monsanto, Syngenta, Bayer, Dupont, Dow AgroSciences e Basf (AL/RS, 2013). Parece evidente que, enquanto política pública, uma articulação efetiva entre empresas, governo e demais atores envolvidos não está em curso, não se vislumbra. De certa forma, isso explica a alta exposição social aos agrotóxicos no Brasil.)

Conforme apontado, não há como determinar a partir dos dados do SIGRA/RS (2013) se o uso de agrotóxico nos assentamentos atende aos limites estabelecidos para cada cultura. Esta observação é ao mesmo tempo um limite e um potencial de pesquisa na área. De qualquer forma, parece interessante apontar que parte importante da produção realizada nos assentamentos emprega agrotóxicos e a correspondência das taxas percentuais destas culturas com os níveis elevados de toxicologia indicados pela Anvisa é uma realidade. Para um enfoque da agricultura ligado ao meio ambiente, como preconizado pela pesquisa agroecológica, com um conceito de produção que garanta a sustentabilidade do ponto de vista ecológico, um estudo mais detalhado das práticas agrícolas em assentamentos seria mais esclarecedor.

No nível global, como já apontado, a taxa de crescimento do uso de agrotóxicos é alta, como ilustra a Figura 4. Os assentamentos da reforma agrária não são imunes, como visto, a este fenômeno. Se a tendência é de aumento, especialmente para o Brasil, é muito pouco provável que o crescente uso de agrotóxicos não se registre a longo prazo nas mais diferentes realidades agrícolas. 


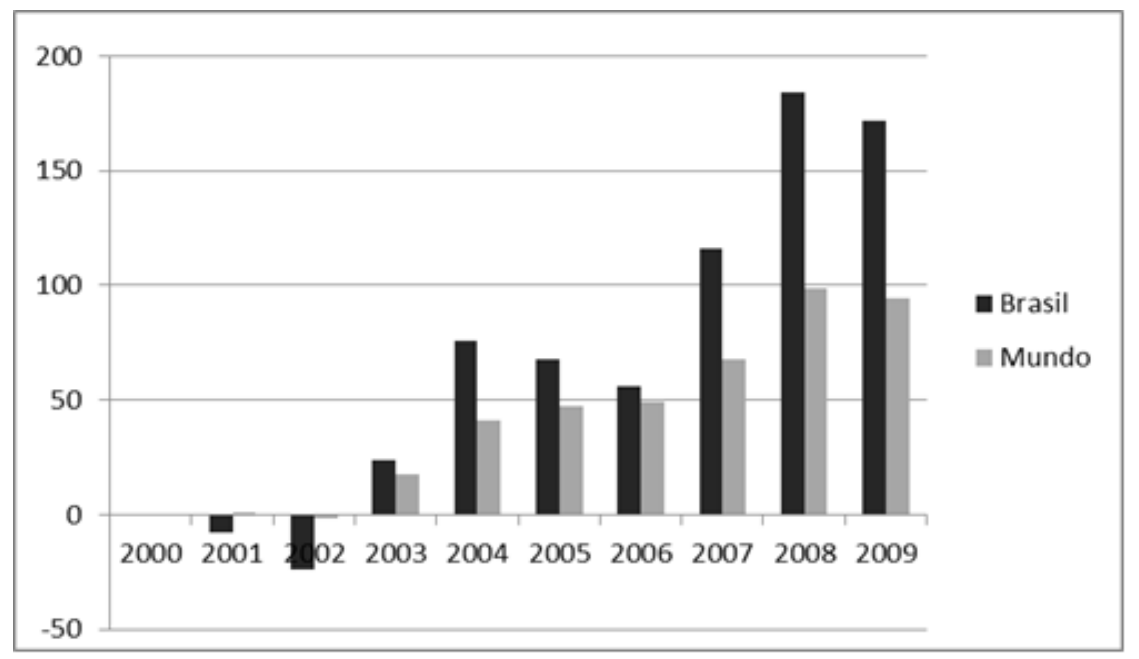

Figura 4: Taxa de Evolução do uso de agrotóxico no Brasil e no mundo (em \%). Fonte: Dados divulgados pela AL/RS (2013). Elaboração própria.

A questão da adoção de agrotóxicos em atividades produtivas, como fora apontado, é apenas uma parcela da discussão agroecológica, muito embora careça de atenção enquanto prática social. Assim como defendido nesta área de estudo, ecossistemas sujeitam-se às práticas humanas, coevoluindo com a sociedade e dando origem ao que se convencionou chamar de agroecossistemas. Esta interação importa. O sentido de sustentabilidade não se sujeita, portanto, ao simplismo da agricultura ecologizada. A temática trabalhada neste artigo é, assim, uma parcela indissociável da visão sistêmica que o fenômeno sustentabilidade defende e abarca.

\section{Conclusões}

A perspectiva agroecológica, como destacado, encerra uma diversidade de conceitos e formulações que não parece satisfazer ao sentido epistemológico sustentado pela ciência convencional ou positivista. Um destes conceitos, aqui considerado o mais importante deste campo de investigação, é o de coevolução. Sob este olhar, a interação sociedade-natureza requer uma análise ampla, que vai muito além dos temas aqui tratados. De qualquer forma, considerando a pertinência desta particular questão, o artigo objetivou contribuir de forma a explorar dados muito recentes sobre uma relação muito pontual da interação sociedade-natureza: o uso de agrotóxicos.

Os registros sobre o uso de agrotóxicos em assentamentos da reforma agrária, disponibilizados pelo Sistema Integrado de Gestão Rural possibilitam a análise de diversos aspectos das famílias assentadas. Constata-se que a possibilidade de cruzamento dos dados poderia potencializar o nível de análise daqueles indicadores. No caso dos agrotóxicos, outros componentes do uso poderiam ser coletados, tais como o tipo ou adequação à cultura. De qualquer forma, enquanto ferramenta de gestão permite avanços em termos de gestão, de pesquisa e assessoria. Para o Programa de Análise de Resíduos de Agrotóxicos em Alimentos (PARA) da Anvisa, resultados técnicos podem ser encontrados a partir de amostras. Estudos desta natureza, se realizados em produtos oriundos de assentamentos, permitiriam avaliar se os índices encontrados neste estudo estão dentro dos limites aceitos, se há combinação indevida por culturas ou se ambos os casos ocorrem.

O trabalho acerca dos dados examinados deixa muito clara a associação existente entre as duas fontes de pesquisa. Objetivamente, se constata que produtos com maior taxa de uso de agrotóxicos em assentamentos são aqueles que maior porcentagem de rejeição amostral apresentam quando analisados pela Anvisa. Nestas culturas agrícolas específicas, como no caso do arroz, a combinação de diferentes tipos de agrotóxicos torna-se recorrente, potencializando a propensão à rejeição por instituições fiscalizadoras e elevando os riscos sociais e ambientais. 


\section{REFERÊNCIAS}

AGÊNCIA NACIONAL DE VIGILÂNCIA SANITÁRIA. Programa de análise de resíduos de agrotóxicos em alimentos. Relatório de atividades de 2011 e 2012. Gerência-Geral de Toxicologia. Brasília, 2013.

ALMEIDA, J. A agroecologia entre o movimento social e a domesticação pelo mercado. Ensaios FEE, Porto Alegre: v. 24, n. 2, 2003.

ALTIERI, M. Agroecologia: bases científicas para una agricultura sustentable. Montevideo: Editorial NordanComunidad, 1999.

ALTIERI, M.; TOLEDO, V. La revolución agroecológica en Latinoamérica. Sociedad Cientifica LatinoAmericana de Agroecologia - SOCLA. 2011.

ASSEMBLÉIA LEGISLATIVA DO ESTADO DO RIO GRANDE DO SUL. Agrotóxico. Cadernos de formação n. 1. Porto Alegre. 2013.

BRASIL. Lei Federal no 7.802. In: http://www.planalto.gov.br/ccivil_03/leis/17802.htm. Acesso em 20 de Janeiro de 2014.

BRASIL. Decreto no 4.074. In: http://www.planalto.gov.br/ccivil_03/decreto/2002/d4074.htm. Acesso em 30 de Janeiro de 2014.

BRITO, P. et al. Agrotóxicos e saúde: realidade e desafios para mudança de práticas na agricultura. Physis Revista de Saúde Coletiva, Rio de Janeiro, n. 19, 2009.

CALDART, R. et al. Dicionário da educação do campo. Rio de Janeiro, Escola Politécnica de Saúde Joaquim Venâncio, 2012.

CAPORAL, F.; COSTABEBER, J. Agroecologia: alguns conceitos e princípios. MDA/SAF/DATER-IICA Brasília, 2004.

CAVALCANTI, C. Concepç̃es da economia ecológica: suas relações com a economia dominante e a economia ambiental. Estudos avançados, 2010.

GLIESSMAN, S. Agroecología y agroecosistemas. Ciência \& Ambiente 27. 2003.

GLIESSMAN, S. R.; et.al. Agroecología: promoviendo una transiciónhacialasostenibilidad. Ecossistemas, v. 16, p. 13-23, 2007.

GOMES, J.; ROSENSTEIN, S. A geração de conhecimento na transição agroambiental: em defesa da pluralidade epistemológica e metodológica na prática científica. Cadernos de Ciência \& Tecnologia, Brasília, v.17, n.3, p.29-57, 2000.

GUSMÁN, S. Agroecologia: bases teóricas de la agroecologia (1999).

A perspectiva sociológica em agroecologia: uma sistematização de seus métodos e técnicas. Agroecol.e Desenv.Rur.Sustent.,Porto Alegre, v.3, n.1, 2002.

GUZMÁN, E.; NAVARRO, M. Ecosociologia: algunos elementos teoricos para el analisis de la coevolucion social y ecologia em la agricultura. In: Leff, E. (ed), La Complejidad Ambiental, Siglo XXI, Mexico, 54-84. 2000.

INSTITUTO NACIONAL DE COLONIZAÇÃO E REFORMA AGRÁRIA. Assentamentos gaúchos vão contar com sistema integrado de gestão rural em 2012. INCRA. Acesso em 18/12/2013. Disponível em $<$ http://www.incra.gov.br/index.php/noticias-sala-de-imprensa/noticias/11770-assentamentos-gauchos-vao-

contar-com-sistema-integrado-de-gestao-rural-em-2012>.

LONDRES, F. Agrotóxicos no Brasil: um guia para ação em defesa da vida. Articulação Nacional de Agroecologia. Rio de Janeiro, 2011.

MINISTÉRIO DO DESENVOLVIMENTO AGRÁRIO. Manual operacional de Ates. INCRA, 2008.

PORTILHO, F. et al. A alimentação no contexto contemporâneo: consumo, ação política e sustentabilidade. Ciência \& Saúde Coletiva, n. 16, 2011

PROGRAMA DE ATES/RS. O programa. Acesso em 04/02/2014. Disponível em <http://www.atesrs.net.br/sobrenos>.

SANTIAGO, S. Incorporando el enfoque agroecológico en las instituciones de educación agrícola superior: la formación de profesionales para una agricultura sustentable. Agroecologia e Desenvolvimento Rural Sustentável. Porto Alegre, v.3, n.2, 2002.

SIGRA/RS. Sistema Integrado de Gestão Rural da ATES. Banco de dados 2013. Integrado ao Programa de Assessoria Técnica, Social e Ambiental (ATES) aos assentamentos de Reforma Agrária. Disponível em: www.sigra.net.br. Acesso em: 11 dez. 2013. 